\title{
A Gestão do Trabalho e os Desafios da Competência: uma Contribuição de Philippe Zarifian
}

The Management of Work and Challenges of Competence: a Contribution by Philippe Zarifian

La Gestión del Trabajo y los Retos de la Competencia: una Contribución de Philippe Zarifian

\section{Claudia Maria Pereira de Lima} Empresa Brasileira de Serviços Hospitalares

Paulo César Zambroni-de-Souza

\& Anísio José da Silva Araújo

Universidade Federal da Paraíba

http://dx.doi.org/10.1590/1982-3703001972013

(cc) BY 
Resumo: As formas de organizar a produção de bens e de serviços vêm sofrendo profundas transformações desde as últimas décadas do século $\mathrm{XX}$, gerando a necessidade de transformar igualmente as teorias e as práticas em Psicologia do Trabalho e Organizacional (PTO). Ocupando um lugar de destaque nas mudanças nos mundos do trabalho e da PTO, coloca-se a noção de competência. Como é comum nas Ciências Humanas e, dentro delas, na Psicologia, tal noção recobre diferentes sentidos a partir de distintas concepções e autores. Nesse artigo optou-se por focalizar as contribuições ao debate sobre competência a partir de um conjunto expressivo de publicações existente em português do Brasil de autoria de Philippe Zarifian, economista e sociólogo francês, cujas ideias têm produzido desdobramentos interessantes em setores da Psicologia do Trabalho e Organizacional brasileira, inspirando a reconfiguração de concepções e práticas vigentes. Verifica-se que o modelo da competência traz consigo possibilidades reais de transformações profundas, possibilitando uma participação implicada dos homens em seus trabalhos. Entretanto, sem cumprir certas condições, tal modelo pode se transformar em mais um meio de exploração e de destruição dos coletivos de trabalhadores.

Palavras-chave: Competência Profissional. Trabalho. Psicologia do Trabalho e Organizacional.

\begin{abstract}
The ways of organizing the production of goods and services have undergone major changes during the last decades of the twentieth century, creating the need to transform the theories and practices of work and organizational psychology (WOP). By occupying a prominent place in the changes in the worlds of work and WOP, the notion of competence exists. As is common in humanities and psychology, this notion covers different meanings from different conceptions and authors. In this study, we chose to focus on the contributions to the debate on competence from a significant number of existing publications in Brazilian Portuguese by Philippe Zarifian, a French sociologist and economist whose ideas have produced interesting developments in the sectors of WOP in Brazil, thereby inspiring a reconfiguration of conceptions and practices. The competency model brings a real possibility of deep transformations, enabling the participation of men involved in their work. However, without meeting certain conditions, such a model of competence can turn into another means of the exploitation and destruction of workers' collectives.
\end{abstract}

Keywords: Professional Competence. Work. Work and Organizational Psychology.

Resumen: Formas de organización de la producción de bienes y servicios han experimentado cambios importantes durante las últimas décadas del siglo XX, creando la necesidad de transformar también las teorías y prácticas en la Psicología del Trabajo y de las Organizaciones (PTO). Ocupando un lugar destacado en los cambios en el mundo del trabajo y de la PTO, se ubica la noción de competencia. Como es común en las Humanidades y, dentro de ellos, en la psicología, esta noción abarca diferentes significados en las diferentes concepciones y autores. En este trabajo se optó por centrarse en las contribuciones al debate sobre las competencias de un número significativo de publicaciones existentes en portugués de Brasil por Philippe Zarifian, sociólogo y economista francés cuyas ideas han producido interesantes avances en los sectores de la Psicología del Trabajo y de las Organizaciones de Brasil, inspirando la re-configuración de concepciones y prácticas vigentes. El modelo de competencia trae posibilidades reales de transformaciones profundas, lo que permite la participación de los hombres involucrados en su trabajo. Sin embargo, sin el cumplimiento de ciertas condiciones, tal modelo puede convertirse en otro medio de explotación y destrucción de los colectivos de trabajadores.

Palabras clave: Competencia Professional. Trabajo. Psicología de Trabajo y Organizacional. 


\section{Repercussão do modelo da competência para o trabalho}

Desde a Revolução Industrial e, mais especificamente, com o taylorismo, o trabalhador foi parcialmente desapossado de sua atividade produtiva, o que significa dizer que perdeu para a gerência o controle que possuía sobre os fins, os métodos e os resultados de seu trabalho. A atividade usurpada Ihe foi devolvida sob a forma do posto de trabalho, ou seja, um lugar e um conjunto de tarefas definidos de forma externalizada, à revelia do trabalhador, e ao qual deveria submeter-se incondicionalmente. A partir de então, o trabalho passou a ser objetivado, analisado, racionalizado, determinado e modificado, independentemente daquele que o realizava. E o trabalhador era apenas um objeto, portador das capacidades funcionais necessárias para realizar esse trabalho (Zarifian, 2003).

Para Zarifian (1997), ao se definir o trabalho como uma sequência de operações objetiváveis, houve uma ruptura radical entre dois objetos: o "trabalho", definido como um conjunto de operações elementares passível de descrição objetiva e racionalização e o "trabalhador", definido como uma força de trabalho, dotado de uma certa energia e de uma certa habilidade, capaz de assumir a realização dessas operações. Diante disso, a qualificação passou a significar uma maneira de classificar a relação entre o trabalho objetivado e as capacidades do trabalhador hierarquizadas por níveis de complexidade. Ela refletia a capacidade do trabalhador de ajustar-se às operações que deveria realizar como assalariado, subordinado a um empregador (Zarifian, 1997; 2003).

Resulta disso a força do conceito de posto de trabalho, porque é nele que se cristaliza essa relação, seu controle e sua avaliação. O posto é, ao mesmo tempo, um lugar e uma função específica na organização, um tempo preciso de duração de trabalho, um conjunto de tarefas a realizar e uma imobilização do trabalhador, sob a pressão do ritmo de produção ou do rendimento de seu posto, contido pela ausência de legitimidade de sua iniciativa pessoal (Zarifian, 2003).
Quando se valoriza a competência, não há uma hierarquia disciplinar que, a todo momento, toma decisões e indica o que se tem a fazer (o que não significa o desaparecimento da hierarquia). Em contrapartida, ganha novo alcance uma forma tradicional de controle do trabalho baseada na definição de objetivos e resultados a alcançar e que se exprime da seguinte forma: o assalariado deve prestar contas regularmente dos seus resultados e os objetivos que lhe são atribuídos podem ser rapidamente reatualizados. Muitos, inclusive, travestem de gestão por competências essa modalidade de exploração contemporânea, na qual se despejam sobre os trabalhadores pesadas metas, exaltando-se o fato de que a gerência abdicou do controle dos métodos, deixando-os a cargo dos trabalhadores.

Verifica-se que, enquanto na fábrica fordista o trabalhador não cessava de recomeçar um mesmo trabalho (com algumas variações), nas empresas contemporâneas a condição típica é a instabilidade, a mudança contínua, ou seja, tudo é passível de revisão, de remodulação contínua, seja o conteúdo do trabalho, sejam as metas ou as aquisições cognitivas do indivíduo (Zarifian, 2002). Com isso, o trabalho não se configura apenas como um conjunto de tarefas associadas a um determinado cargo, por sua vez ocupado por um trabalhador, mas se torna o prolongamento direto da competência que o indivíduo mobiliza em face de uma situação profissional, cada vez mais mutável e complexa. A complexidade das situações transforma o imprevisto em algo cada vez mais frequente (Fleury \& Fleury, 2001), a ponto de se poder afirmar, como Zarifian (2001b), que trabalhar é fazer face aos eventos.

Para Borges (2006), o trabalho não pode mais ser visto como uma sequência de operações programadas, padronizadas e repetitivas, já que se tornou uma sequência de eventos que se cruzam, se modificam e ultrapassam, em muitos casos, o saber e a ação de um único indivíduo, levando-o a mobilizar uma rede de atores em busca de um entendimento recíproco sobre a situação enfrentada, pré-requisito de uma ação pertinente. 


\section{Emergência e contribuições do modelo da competência}

O modelo da competência constitui uma transformação de longo prazo que, embora já venha se desenvolvendo há algum tempo, ainda pode ser considerado um modelo emergente, em processo, buscando conquistar o seu lugar no pensamento gerencial contemporâneo. Não se pode, entretanto, ao destacar a importância do modelo da competência, afirmar que tudo que existe na galeria das novidades organizacionais e que inclui a palavra competência espelhe de fato as mutações nos mundos do trabalho. Muitos supostos sistemas de gestão de competências são apenas formas modernizadas do modelo do posto de trabalho. Como o próprio Zarifian (1996a) assinala de maneira crítica, "chama-se de formação e gestão de competências as práticas bem tradicionais, que consistem em definir as capacidades que um indivíduo deve possuir para ocupar um posto de trabalho" (p. 15).

É inegável que a abordagem do posto de trabalho conheceu (e ainda conhece, embora não mais hegemonicamente) um grande alcance, pois permitiu a massiva integração na indústria de pessoas sem experiência industrial favorecendo a objetivação da qualificação e tornando-a, assim, relativamente independente das características particulares das pessoas que ocupavam os empregos, além de ter permitido a circulação do conhecimento profissional, graças aos referenciais de formação e aos manuais de treinamento que fez surgir (Zarifian, 1996a). Entretanto, essa abordagem tem efetivamente pouco a dizer a respeito das competências do indivíduo. Nesse artigo, defende-se que avalizar uma compreensão de competência enquanto conjunto de habilidades e requisitos deduzidos do cargo, na linha do que reza a cartilha taylorista, não atende às demandas atuais das organizações complexas e mutáveis do mundo globalizado.

Pode-se falar na emergência do modelo da competência por volta dos anos de 1985/86, quando se operaram mudanças significativas nas demandas sobre os trabalhadores (a "mão de obra"). Por ter sido este um momento que coincide com a perda e fragilização dos vínculos empregatícios em vários países, consequente às crises econômicas dos anos 1970, pode-se facilmente confundir competência com precarização, ou até mesmo justificar a segunda com argumentos de "incompetência" dos trabalhadores. No entanto, na proposta defendida no presente artigo, seguindo Zarifian (2003), o modelo da competência exige a valorização do trabalhador em uma situação na qual a empresa oferece segurança para que os trabalhadores possam desenvolver suas competências.

A noção de mão de obra, mantida propositalmente aqui, carrega em si a marca do taylorismo, na medida em que promove uma separação entre alma/cérebro (sede do pensamento, da concepção) e o corpo (lugar da mobilidade, da execução de tarefas). Nesse contexto, a mão de obra era avaliada e gerenciada segundo suas habilidades corporais, tais como destreza e rapidez na execução das tarefas. As mudanças nos mundos do trabalho tornaram evidente que a empresa não podia se sustentar na cabeça de uns poucos (os planejadores) e no corpo do restante (a maioria), mas precisava da inteligência e da subjetividade do conjunto. Segundo Zarifian (2001b), passava-se, assim, da solicitação do corpo à solicitação do cérebro.

Tais mutações, entretanto, não ocorreram no vazio, mas foram a resposta a um vasto conjunto de mudanças econômicas, políticas, sociais e subjetivas que culminaram com a derrocada do fordismo e deflagraram a prospecção de uma nova estratégia do capitalismo que abrisse um novo horizonte. Nesse sentido, é preciso situar esse terreno que favoreceu uma série de mudanças no modo de governar as empresas, em que o modelo da competência figura em destaque.

A crise de 1929 nos EUA e o estrago que causou no mundo capitalista fizeram com que, pelo menos por um tempo, o caminho de radicalização do liberalismo sofresse um desvio, o que se refletiu na construção de um pacto social que envolveu Estado, empresários e trabalhadores e pelo qual cada um 
desses segmentos abdicou de algo que the era precioso para restituir alguma chance de sobrevivência ao sistema capitalista. As saídas encontradas, tais como a restituição do protagonismo do Estado na geração de empregos e na condução da economia, a constituição do chamado Estado de Bem-Estar Social, protegendo o trabalhador das instabilidades, ao lado de outras medidas, foram responsáveis por um crescimento sustentado do capitalismo durante os chamados "trinta gloriosos", do pós-segunda guerra mundial até meados dos anos 1970. Até então, portanto, a ampla fórmula fordista funcionava sem grandes atropelos, embora já exibisse sinais de esgotamento. Depois disso, uma conjunção de fatores desfavoráveis apresentados por Heloani (2003) precipitou o capitalismo em nova grave crise, forçando a revisão da estratégia até então adotada. Eis alguns desses fatores:

- Queda na produtividade do trabalho: decorrente da tecnologia-rígida-própria do fordismo e da insatisfação dos trabalhadores com a gestão fordista, top down, e cujas expressões mais evidentes foram as altas taxas de absenteísmo e de rotatividade, o crescimento do desinteresse pelo trabalho, das greves e de outras formas silenciosas de protesto;

- Elevação dos níveis de inflação: o capital não suportava mais o ônus da elevação do salário real que marcou o período fordista, repassando os aumentos de custos aos preços, provocando inflação e, consequentemente, perda do poder aquisitivo dos trabalhadores;

- Esgotamento dos mercados consumidores: redução dos investimentos, do ritmo de crescimento econômico, ocasionando desemprego. A produção em larga escala exibe sinais de cansaço, sendo a parada na produção do fusca a sinalização mais evidente da necessidade de uma nova estratégia do capital. A lógica fordista - 'automóvel de qualquer cor, desde que seja preto' - se apresentou incapaz de responder aos desafios que dominavam aquele contexto e pedia substituição;

- Desaceleração do crescimento econômico: a redução no recolhimento de tributos ocasionada pela desaceleração econômica produziu em consequência o aumento dos gastos sociais, a elevação do déficit público e dos níveis de inflação;

- Fim do padrão ouro e da conversibilidade do dólar: a instabilidade nos mercados de câmbio, financeiro e de produtos levou ao questionamento da hegemonia americana, abrindo espaço à participação da Alemanha e do Japão no comércio mundial;

- As crises do petróleo de 1973 e 1979 foram responsáveis por um grande reajuste dos preços dos derivados de petróleo, redundando em alta dos níveis inflacionários;

- Por fim, a elevação das taxas de juros americanas provocou, especialmente nos países subdesenvolvidos e em desenvolvimento, como o Brasil, um crescimento vertiginoso do endividamento externo, configurando um quadro de dependência permanente em relação aos países credores.

Esse cenário desequilibrou profundamente a equação fordista e decretou o fim dos anos de ouro. A relativa estabilidade que marcou esse período cede lugar a um ambiente de incertezas. Aos tempos futuros grandes dificuldades estavam reservadas, especialmente para os que vivem do seu trabalho. Tudo levava a crer que o lugar que os trabalhadores ocuparam, através de seus representantes sindicais, na negociação social, havia chegado ao fim, configurando uma grave crise do sindicalismo.

As respostas à crise situaram-se basicamente em três planos: no plano político, o neoliberalismo; no plano econômico, a globalização financeira; no plano da produção e do trabaIho, a reestruturação do sistema produtivo. Nesse último plano, situamos a introdução do modelo da competência que, ao lado de outras mudanças, buscavam quebrar um ciclo de queda de produtividade do trabalho.

O termo competência mostrava-se mais apropriado para expressar as novas demandas requeridas dos trabalhadores pelo sistema produtivo, tais como iniciativa, flexibilidade, 
polivalência, multifuncionalidade, cooperação e autonomia. A disseminação desse conceito no mundo empresarial possui como móvel fundamental a necessidade de sobrevivência das organizações em ambientes competitivos que, por sua vez, dependem cada vez mais da rapidez das respostas empresariais às diversas demandas ambientais. Essa rapidez leva as empresas a assumirem formas organizacionais mais fluidas e menos prescritivas de modo a otimizar os tempos de resposta (Amaro, 2008).

Evidencia-se, assim, a crise da prescrição: os métodos, procedimentos, normas se encontram cada vez mais desajustados, não apenas em face dos saberes efetivamente mobilizados nos atos reais de produção, mas em relação ao caráter crescentemente circunstancial, complexo e imprevisível dos problemas a resolver no plano da atividade concreta (Zarifian, 1995a).

A questão da competência, portanto, está diretamente atrelada à crise do modelo da prescrição, aparecendo primeiramente nas empresas que tentaram sair da crise econômica pela elevação da qualidade e da diversidade de seus produtos e pelo aumento da frequência de suas inovações (Zarifian, 1996a). $\mathrm{Na}$ impossibilidade de prever e controlar, por meio da prescrição, o comportamento dos trabalhadores, a lógica da competência, sustentada na tomada de iniciativa e no assumir de responsabilidade, aparece como uma solução à questão da eficácia e eficiência das empresas (Zarifian, 2001a).

De acordo com Zarifian (2003), a iniciativa significa a competência em si mesma, em ação, o engajamento do sujeito não em relação a regras - sejam elas determinadas ou autônomas - mas em relação a um horizonte de efeitos, aqueles que sua iniciativa singular provoca. Entretanto, para que a tomada de iniciativa seja bem-sucedida, dois fatores revelam-se cruciais: os recursos internos pessoais que o indivíduo adquiriu e que solicita e desenvolve em dada situação; e os recursos coletivos, disponíveis sob formas diversas nas situações de trabalho, por vezes disponibilizados pela organização, tais como o incentivo ao apoio dos colegas, as guias ou procedimentos, os casos de iniciativas bem-sucedidas em situações parecidas, as formações, entre outros. Assim, cabe à empresa favorecer o desenvolvimento desses dois tipos de recursos (Zarifian, 2003).

Para Zarifian (1996a), aumentar a competência é, antes de tudo, criar as melhores condições para que os trabalhadores aceitem assumir responsabilidades e se mobilizem subjetivamente. Significa igualmente criar condições para que seus superiores hierárquicos aceitem delegar uma parte de suas responsabilidades. Nesse sentido, é um problema de organização do trabalho, de repartição dos poderes e de funcionamento social, antes de ser um problema de formação.

O pleno desenvolvimento das competências exige, segundo Zarifian (2001b), o atendimento a condições como estabilidade do emprego e segurança (dentro e fora da empresa); a possibilidade do trabalhador adotar uma postura reflexiva em relação a sua atividade; o aprofundamento da formação, geral e profissional; o pleno reconhecimento, salarial e simbólico, da adoção da lógica competência (Zarifian, 2001a) de modo que o trabalhador possa assumir suas responsabilidades no processo produtivo. Este assumir responsabilidade significa, para Zarifian (2003), responder por, ou seja:

[...] ir até o fim de sua tomada de iniciativa. [...] assumir a plenitude de sua ação em face dos outros, mas também (e primeiramente) em face de si mesmo. Respondo pela minha iniciativa. Em outras palavras, respondo por seu alcance, por seus efeitos e por suas consequências. Exerço minha potência até nas suas consequências (p. 139).

Este assumir responsabilidade corresponde a uma atitude social de implicação, no sentido em que mobiliza fortemente a inteligência e a subjetividade da pessoa. Significa também assumir riscos, pois toda pessoa que aceita assumir responsabilidades corre o risco de fracassar e, então, de sofrer uma avaliação negativa por parte da hierarquia e de seus colegas de trabalho (Zarifian, 1996a). 


\section{Evento, comunicação e serviço}

Segundo Zarifian (2001b), contribuíram para a emergência do modelo da competência três grandes mutações que, no seu entender, sintetizam a nova face do mundo do trabalho: as noções de evento, comunicação e serviço.

Um contexto econômico turbulento e de crescente complexificação das tecnologias e dos produtos, um ritmo rápido de renovação são os ingredientes para tornar a incerteza um atributo familiar, constante no mundo atual, ao invés de episódico, pontual, como certamente o fora outrora. Incerteza que, por sua vez, se espalha sobre a economia e a evolução dos mercados, que se reflete nas variações quantitativas e qualitativas das encomendas dos clientes e na transformação e mobilidade dos costumes (Zarifian, 2001a). Reagir a todas essas variabilidades ou, melhor ainda, enfrentá-las é o desafio urgente dos novos tempos.

Diante dessa nova realidade, a noção de evento adquire força ao mesmo tempo em que desestabiliza o esquema do trabalho industrial clássico. Desse modo, a competência profissional não pode mais ser enclausurada em definições prévias de tarefas a executar em um posto de trabalho, mas consiste em fazer frente aos eventos de maneira pertinente e com conhecimento de causa (Zarifian, 2001a).

Segundo Zarifian (1996b), a noção de evento apela para a mobilização das competências dos trabalhadores para resolver os imprevistos que surgem nas situações de trabalho. A noção de evento substitui aquela de operação de trabalho ou de tarefa prescrita (Zarifian, 1991), pois nela valoriza-se o que é da ordem do não totalmente previsível, nem mesmo, algumas vezes, provável. Logo, valoriza-se o que é da ordem do não totalmente reproduzível, ou seja, da ordem do criativo. Essa noção também repercute na maneira de encarar as aprendizagens profissionais e de avaliar a experiência de cada assalariado. O tempo de exercício de uma atividade profissional não é mais um critério discriminante para a avaliação da qualificação, que passa a estar ancorada na capacidade de enfrentamento de uma variedade de eventos. É, portanto, a multiplicidade de situações enfrentadas e as aprendizagens obtidas desses enfrentamentos que constituem os ingredientes da "nova" qualificação.

É importante ressaltar que o evento sempre fez parte da vida das organizações, embora na atualidade apresente-se com uma frequência, intensidade e complexidade muito elevadas, a ponto de se poder afirmar que assistimos aí uma ruptura qualitativa em relação aos padrões outrora vigentes. Acredita-se que ele deve ser encarado como oportunidade para demonstrar a potência do trabalho humano em inventar as respostas a serem dadas em um ambiente social complexo e instável. Trabalhar nessas condições é, fundamentalmente, estar na expectativa desses eventos, pressenti-los, enfrentá-los quando aparecerem e empenhar-se na sua superação. O trabalho revela-se, assim, como a ação competente do indivíduo diante de uma situação de evento (Zarifian, 2001a).

Dependendo da complexidade do evento, este pode ultrapassar o saber e a ação de um indivíduo isolado, exigindo a mobilização de uma rede de atores que terá, por sua vez, maiores chances de construir uma compreensão pertinente e de intervir em bases mais favoráveis. Essa intensa mobilização só pode ocorrer se já existirem relações anteriores entre esses atores, se as competências, as trocas verbais, as atribuições puderem ajustar-se entre si no seio dessa rede. O trabalho é, assim, assumido como coletivo.

Compreende-se que o trabalho torna-se o prolongamento direto da competência pessoal que um indivíduo mobiliza em face de uma situação profissional, isto é, diante de uma pane, de um problema apresentado por um cliente ou do sucesso de uma inovação. Trabalhar torna-se, simultaneamente, a aplicação concreta de uma competência individual, a inserção em processos de socialização que permitem inclusões sociais e profissionais e a colocação em comunicação e colaboração conjunta de um conjunto de competências individuais (Zarifian, 2001a). 
Diante disso, merece destaque a noção de comunicação que se torna um componente essencial do trabalho, a ponto de se poder afirmar que nas atuais circunstâncias "trabalharé, em parte pelo menos, comunicar-se" (Zarifian, 2001 a, p. 45). A comunicação está atrelada à necessidade das pessoas compreenderem o outro e a si mesmas para partilharem objetivos e normas organizacionais. Comunicar-se é construir um entendimento recíproco e bases de compromisso que serão a garantia do sucesso das ações desenvolvidas em conjunto (Zarifian, 2001a).

A comunicação também pressupõe conflitos, que podem ser considerados positivos quando a partir deles se pode chegar a um melhor entendimento e à obtenção de solidariedades de ação mais sólidas, desde que sejam encarados como uma autêntica prática de comunicação, que leva mais a compromissos do que a consensos (Zarifian, 2001a).

No que se refere à noção de serviço, esta implica em considerar que trabalhar é gerar um serviço, provocando modificação no estado ou nas condições de atividade de outro humano ou de uma instituição, a quem chamaremos de destinatários do serviço, seja ele um cliente no setor privado ou um usuário no setor público, de maneira que responda às necessidades e expectativas deste último (Zarifian, 2001a, 2001b, 2001c).

O serviço é uma organização e uma mobilização de recursos, a mais eficiente possível, para interpretar, compreender e gerar a mudança perseguida nas condições de atividade do destinatário do serviço chamado de cliente-usuário (Zarifian, 2001b). Os efeitos julgados pelo destinatário na transformação realizada nas condições de sua atividade e nas suas disposições de ação são discutidos, concebidos e gerados graças à competência dos assalariados da empresa oferecedora (e com a possível colaboração do destinatário). Esse serviço se torna, então, fonte de renda para a empresa que o produz (Zarifian, 2003). Não se trata de considerar serviço um setor (o terciário) tal qual o setor secundário (da indústria) ou ainda o setor primário (da agricultura), mas entendê-lo como algo que concerne ao trabalho contemporâneo, qualquer que seja o setor de atividade (Zarifian, 2001a).

Dessa forma, qualquer que seja o universo da produção, a competência de serviço tem adquirido importância. Ela representa, sobretudo, uma abertura e uma transformação interna dos ofícios já existentes. Exemplificando: não se trata de pedir a um analista de recursos humanos para ser outra coisa além de um analista, mas para o ser de uma forma diferente. Zarifian (2001b) indica que desenvolver uma competência é perguntar-se de que maneira o produto (o bem ou o serviço) beneficiará utilmente os destinatários.

Afirmar que trabalhar consiste em produzir um serviço para um destinatário tem a vantagem de tornar concretos os conceitos de cliente ou usuário. Como consequência, considera-se o serviço prestado como um produto oferecido a destinatários precisos, com utilizações claramente definidas, levando em consideração os problemas dos destinatários, bem como os usos concretos que poderão fazer do produto em suas próprias atividades (Zarifian, 2001a). O serviço é, indiretamente, o que justifica a sobrevivência de uma organização e, consequentemente, o emprego dos assalariados. Por isso, a produção de serviço é essencial para a produção contemporânea, pois é aquela que irá conferir sentido e pertinência a esta última.

No âmbito de uma lógica de serviço, a qualidade é definida em função da maneira como um produto melhora qualitativamente as condições de produção ou de vida de um cliente (Zarifian, 2001b). Com isso, a competência profissional revela-se decisiva na produção do serviço, pois é preciso interpretar e compreender as expectativas do cliente-usuário quanto aos resultados a serem gerados. Desde o início, também, é preciso conhecer a atividade do destinatário, para agir com pertinência sobre as suas condições de execução. É nessa interação social que se situa a especificidade da atividade e da responsabilidade humana, pois nenhum maquinário pode substituí-la (Zarifian, 2001b). 


\section{Competência(s): que definições, que compreensões?}

Para Zarifian (2003), a competência constitui uma nova forma de qualificação, ainda emergente. $\mathrm{O}$ assalariado é duplamente qualificado: em relação à sua contribuição para a eficiência de um processo de produção e também quanto ao seu lugar na hierarquia salarial.

Alguém é tanto mais qualificado, segundo Zarifian (2003), quanto mais é autônomo no seu trabalho, definindo por si mesmo as regras (leis) de sua própria ação. É uma verdadeira inversão de valores em relação à tradição taylorista. A diminuição das normas se torna algo benéfico, o que mostra, indiretamente, que os empregos com muitas normas são, se não um mal, pelo menos uma situação pouco desejável e valorizada.

É importante ressaltar que, embora necessária, a questão de ser autônomo não é suficiente para caracterizar o problema da competência, ou seja, um indivíduo pode estar em situação de grande autonomia e, ainda assim, se revelar incompetente (Zarifian, 2003). A relevância dispensada à autonomia remete ao reconhecimento do lugar e do papel da individualidade. Cada indivíduo tem aspirações e capacidades de julgamento que lhe são peculiares e que não podem ser negadas, sufocadas e dissolvidas no interesse coletivo. Embora pareça haver um avanço com essa compreensão, é importante salientar que ela traz consigo implicações sociais que serão discutidas posteriormente.

A autonomia é uma condição inevitável do desenvolvimento da competência, mas o cerne desta última reside, no entanto, na tomada de iniciativa (Zarifian, 2003). Para Zarifian (1996a), deve-se evitar que a avaliação das competências derive para análises de prescrições de comportamento que são sempre, desde seu princípio, contestáveis, porque contraditórias com o princípio moderno de autonomia individual.
Ao definir competência, Zarifian (2001a) centra-se na mudança de comportamento social dos seres humanos em relação ao trabalho e sua organização, apresentando três definições complementares desse conceito:

- A competência é o tomar iniciativa e o assumir responsabilidade do indivíduo diante de situações profissionais com as quais se depara (p. 68);

- A competência é um entendimento prático de situações que se apoia em conhecimentos adquiridos e os transforma na medida em que aumenta a diversidade das situações (p. 72);

- A competência é a faculdade de mobilizar redes de atores em torno das mesmas situações, é a faculdade de fazer com que esses atores compartiIhem as implicações de suas ações, e fazê-los assumir áreas de corresponsabilidade (p. 74).

Posteriormente, o próprio Zarifian (2003) complementa a primeira definição de competência, com destaque à noção de evento: "Competência é a tomada de iniciativa e o assumir de responsabilidade do indivíduo sobre problemas e eventos que ele enfrenta em situações profissionais" (p. 139).

Em sua proposta de aplicação do modelo da competência, Zarifian (2003) exemplifica cinco tipos de situação: as situações de base, que constituem o domínio básico de determinada profissão; as situações ocasionais, que acontecem de forma relativamente imprevista e que a partir delas a tomada de iniciativa se condensa de maneira mais forte, frequentemente por causa de uma situação de emergência; as situações de inovação, que permitem desenvolver explicitamente a inventividade e participar das inovações introduzidas na entidade; as situações de balanço, que formalizam, de certa maneira, os tempos de descanso e a reconsideração da maneira de trabalhar e de sua organização, ou seja, um momento reservado para abordagem reflexiva; e as situações formadoras, aquelas em que o indivíduo é levado a transmitir seu "saber-fazer" e seus conhecimentos, seja participando de uma sessão de formação, seja por meio 
de qualquer tipo de ajuda ou orientação prestada às pessoas. A proposta de aplicação do modelo da competência é constituída por seis etapas, segundo Zarifian (2003):

- A primeira etapa consiste na explicitação da estratégia da organização, o que envolve fixar o quadro e a orientação a ser dada às competências desenvolvidas nessa entidade;

- A segunda etapa refere-se à explicitação das escolhas/opções que irão materializar a estratégia da organização;

- Na terceira etapa, definem-se princípios simples, que caracterizam o que se entende por competência;

- A quarta etapa consiste na elaboração de uma primeira definição das áreas de competência, em termos de competências técnicas (da profissão), competências organizacionais, competências de inovações e competências relacionais;

- A quinta etapa consiste em fazer uma análise das situações (de base, ocasionais, de inovação, de balanço e formadoras) com os interessados;

- E na sexta etapa, há a validação das áreas de competência e hierarquização dos seus níveis, em função dos critérios relacionados ao nível de iniciativa, nível de ampliação do campo de responsabilidade, nível de implicação na cooperação e nível de rigor.

No modelo da competência, a organização é um agregado de iniciativas e de papéis e, portanto, de indivíduos portadores potenciais dessas iniciativas, logo, de competências. Há a compreensão de que os indivíduos competentes não são simplesmente alocados em uma organização: eles a produzem e são competentes dentro da organização e em relação a ela. O outro entendimento é que na organização há um controle hierárquico da orientação e dos efeitos esperados das iniciativas dos indivíduos que a constitui (Zarifian, 2003).

Para Zarifian (1999), ao invés dos assalariados de uma organização manterem com ela uma atitude passiva, eles podem se tornar os atores explícitos do desenvolvimento da organização, contribuindo não apenas para uma competência na organização, mas para uma competência sobre a organização. Trata-se, nesse caso, de uma competência organizacional, quer dizer: competência sobre a organização. As pessoas não devem ser apenas competentes na organização (respeitando um modelo prescrito), mas competentes sobre a organização para serem capazes de pensar elas próprias na sua transformação (Zarifian, 1995b).

Em um contexto marcado por transformações múltiplas e incessantes, as organizações produtivas devem acompanhar esse movimento adequando-se ou mesmo tendo um papel protagonista nessas transformações. Uma competência sobre a organização não é redutível a uma simples competência da regulação cotidiana da distribuição do trabaIho. É preciso, para além disso, conhecer os parâmetros e princípios de funcionamento da organização produtiva em que se trabalha, e saber participar em sua redefinição quando o contexto assim o exigir (Zarifian, 1999).

\section{Implicações sociais e desafios do modelo da competência}

O modelo da competência apresenta-se como uma "saída por cima do taylorismo", como afirma o próprio Zarifian (1996a), pois oferece contribuições significativas ao processo de trabalho ao incentivar a autonomia, a iniciativa, o assumir de responsabilidade, permitindo "uma volta da atividade no sujeito que age" (Zarifian, 2003, p. 77). Apesar desses avanços, é necessário reconhecer que a importância crescente da competência traz consigo uma série de implicações sociais e inúmeros desafios que precisam ser enfrentados.

A emergência atual do modelo da competência se encontra diante de um paradoxo, pois as bases práticas para entender esse modelo ainda são frágeis; muitos supostos sistemas de gestão das competências ainda são apenas formas modernizadas do modelo do posto de trabalho, ou seja, das descrições e classificações de emprego, associadas a requisitos 
de capacidade, aos quais se acrescenta uma camada de saber-ser (Zarifian, 2003).

É impossível enfrentar os novos desafios produtivos e concorrenciais permanecendo encerrados nos limites do posto de trabalho. Ninguém sabe exatamente como se faz para sair do modelo do posto de trabalho, mas todos sabem que é preciso fazê-lo. $\mathrm{O}$ modelo do posto revela não somente sua ineficiência e sua inadaptação, uma vez que grande parte das qualidades efetivamente mobilizadas pelos assalariados não são mais rubricadas pelos descritivos do posto, pois ultrapassam amplamente a oposição clássica entre o real e o prescrito; mas também revela sua injustiça diante do empregador porque as competências reais não são reconhecidas nem remuneradas (Zarifian, 2003).

Diante disso, os desafios se tornam mais evidentes: como reposicionar de modo prático o princípio de subordinação do assalariado em relação ao empregador, que é justamente constitutivo da relação salarial? Que lucro essa mobilização da inteligência pode trazer a uma diretoria de empresa e para os trabalhadores? Como tratar fenômenos de generalização, de crescimento da abstração, de socialização dos conhecimentos, que fizeram a força do taylorismo?

De acordo com Zarifian (2003), é necessário que o assalariado possa responder a questões como: "O que se espera de mim?", "Em que posso contribuir?", "Até que ponto eu devo envolver-me?". Pois são as respostas a esses questionamentos que irão fornecer o caminho para que ele também possa reapropriar-se da pertinência coletiva, controlando, ao mesmo tempo, seu engajamento.

Zarifian (2003) considera que o modelo da competência só pode (epoderá) desenvolver-se plenamente se novos princípios econômicos se impuserem e fizerem da tomada de iniciativa o fator central de sucesso. Merece destaque, então, a relação de serviço que se define como uma busca da transformação positiva nas condições de atividades e nas disposições de ação dos clientes-usuários, interferindo nas escolhas de modo de vida e na mobilidade dos usos.
Outro desafio a enfrentar diz respeito às novas tecnologias da informação que se por um lado oferecem um poder inédito de acompanhamento e de apoio, por outro lado também apresentam um risco de negação da competência por efeito de substituição da ação humana pelo sistema informático, por ruptura dos contatos sociais e por clivagens nas possibilidades de acesso e de interpretação das informações. Ver os sistemas de informação como um apoio e acompanhamento do desenvolvimento da competência, $\mathrm{e}$ não como sua negação, é um grande desafio no período atual (Zarifian, 2003).

Para o autor, o futuro do modelo da competência dependerá muito da maneira como a iniciativa e a responsabilidade conseguirão articular-se, uma em referência à outra (com o risco permanente, em uma relação salarial, de que a responsabilidade sufoque a iniciativa). Nesse sentido, não se sabe ao certo o que esse modelo possa vir a ser no futuro, mas não se deve esquecer de que ele é e será o que os sujeitos e atores fizerem dele. A utilização nefasta da competência em algumas empresas tende a enfraquecer as dimensões sociais e conceituais da qualificação, forjando um trabalhador cada vez mais individualizado e desarraigado dos estatutos sociais do trabalho construídos historicamente.

Como a noção de competência evoca os saberes ligados à trajetória de cada indivíduo, pode levar a desvincular o indivíduo dos códigos das profissões e das classificações no plano da hierarquia social. À medida que essa relação se dissolve, a competência passa a ser esse código. No limite, isso levaria à individualização das relações de trabalho e à responsabilização do indivíduo em relação às suas competências (Ramos, 2001).

Como a competência está remetida ao indivíduo, às suas habilidades, aos seus saberes, corre-se o risco de se requerer e valorizar as avaliações individualizadas, que acabam por destruir os coletivos. A competência é requisitada precisamente quando os padrões de referência dos organizadores ou dos teóricos se mostram discrepantes em relação às demandas concretas. É justamente aí que se situa o risco 
da abertura para uma abordagem individualizada da competência, que acaba facilitando a dissolução dos coletivos e culpabilizando o trabalhador pelos fracassos no trabalho.

De acordo com Stroobants (2006, p. 78), a própria noção de competência nunca entrou em "acordo sobre uma definição rigorosa", o que pode trazer consigo diversos problemas, em especial, a individualização dos processos de avaliação. Isso ocorreria já que, mesmo que se requeira "[...] a faculdade de mobilizar rede de atores em torno das mesmas situações, [...] a faculdade de fazer com que esses atores compartilhem as implicações de suas ações" (Zarifian, 2001a, p. 74), a compreensão de que a competência é específica a cada sujeito que trabalha, poderia resultar na necessidade de avaliação individual. Portanto, corre-se o risco de se entender que cada trabalhador deve ser avaliado individualmente, sem considerar suficientemente as condições e a organização do trabalho e a possibilidade de compartilhar seus saberes e dúvidas com os outros. De fato, há sempre o risco de listar exaustivamente as competências e remetê-las inteiramente à pessoa, como critica Schwartz e Durrive (2010). Tal prática estaria de acordo com as formas de gestão contemporâneas que privilegiam a avaliação individual, assim como a chamada gestão pela qualidade. Estas estimulam que cada um procure sempre produzir mais, incitam a competição e desvalorizam a cooperação, tendendo a destruir os coletivos, deixando cada um à sua própria sorte, fragilizados (Dejours, 2013).

O próprio Zarifian (2003) reconhece que, toda vez que se examina a questão do modelo da competência, evoca-se, com toda razão, a existência de riscos de decomposição dos vínculos sociais e das pertinências coletivas, o risco de uma individualização desenfreada. Por isso, a questão da individualidade não pode surgir sem engendrar suspeitas, pois a relação no nível do indivíduo passa a desconstruir as solidariedades e garantias coletivas, enfraquecendo os assalariados e os sindicatos.

Deve-se salientar que concentrar o problema no indivíduo é se proteger contra uma reflexão crítica que questione a realidade e que exime as organizações do trabalho de sua responsabilidade na criação de um ambiente propício para o desenvolvimento das competências de seus trabalhadores. Observa-se, também, a ocorrência de exigências cada vez crescentes de capacitação contínua dos trabalhadores até as precarizações dos vínculos sociais advindas dessas novas exigências, o que deixa os trabalhadores em uma situação fragilizada.

Nesse sentido, apesar da importância dos títulos e diplomas para a inserção profissional inicial, estes não são fatores determinantes para a permanência dos assalariados no mercado de trabalho. Essa permanência passaria a ser função das competências adquiridas, validadas e permanentemente atualizadas. Com isso, Zarifian (1995b) chama a atenção que não serão apenas os adultos inseridos na vida ativa que sentirão as consequências de exigências cada vez maiores para os trabaIhadores, haja vista que a antiguidade não é mais critério discriminante para a avaliação da qualificação, pois um trabalhador que durante vinte ou trinta anos desempenhou as suas funções, poderá ser declarado incompetente e pressionado a deixar o seu posto, sendo marginalizado na organização do trabalho ou colocado fora dos circuitos e formas de modernização; mas também os jovens que abandonaram o sistema educativo sem diploma, bem como aqueles considerados pelos empregadores com insuficiente escolaridade serão socialmente declarados incompetentes, sem mesmo terem podido mostrar as suas capacidades.

O resultado é a invalidação dos trabalhadores que estão envelhecendo, demasiado idosos ou não suficientemente formados para serem reciclados. Quanto aos jovens, a empresa falha em sua função integradora, pois, ao elevar o nível das qualificações exigidas para a admissão, ela desmonetariza uma força de trabalho antes mesmo que tenha começado a servir, $\mathrm{e}$ os jovens acham-se condenados a vagar de um estágio/pequeno serviço a outro. Ao contratar jovens superqualificados - exigência que não corresponde aos imperativos técnicos -, condena os não qualificados ao risco do desemprego, visto que os postos que poderiam 
ocupar estão tomados por outros mais qualificados. Por esse motivo, Zarifian (1995b) acredita que se está diante de um dilema: se, por um lado, as novas organizações constituem uma oportunidade de abertura a qualificações mais elevadas, por outro lado, elas poderão degradar completamente a situação de um considerável número de indivíduos, o que é preocupante.

Outro ponto a refletir é a mudança profunda do comportamento social dos trabalhadores inseridos na lógica competência (Zarifian, 2003). Uma vez que a competência está relacionada à iniciativa e ao assumir responsabilidade, isto significa que para o trabalhador (ou para sua equipe) assumir responsabilidade é aceitar ser julgado e avaliado pelos resultados obtidos no campo dos desempenhos pelos quais é responsável. Logo, é comprometer-se, tornando-se explicitamente devedor dos resultados de sua atividade, inclusive correndo riscos, pois se estará submetido à avaliação constante do seu desempenho. Isto quer dizer que, caso a estrutura organizacional não mude sua atitude e não forneça meios e garantias mínimas para o trabalhador, como estabilidade, ao menos relativa, do emprego, delegação de confiança por parte da chefia, reconhecimento simbólico e eventualmente pecuniário, facilmente o trabalhador hesitará em assumir essa responsabilidade.

Diante disso, mostra-se evidente que a adoção do modelo das competências traz implicações para o trabalhador, ora com aspectos positivos, como a valorização do trabalho, que assume um caráter mais intelectualizado e menos prescritivo, e a valorização dos saberes em ação, como a inteligência prática dos trabalhadores; ora com aspectos questionáveis, quando a sua má utilização implica uma culpabilização injusta de indivíduos e o aumento do número de excluídos, entre outros.

Por isso, há a necessidade indiscutível de se ter clareza dos inúmeros desafios que estão colocados a partir do modelo da competência para que eles possam ser superados na transformação de organizações de trabalho que favoreçam o desenvolvimento pleno do ser humano.

\section{Conclusão}

Esse artigo procurou apontar a emergência do modelo da competência e os limites por ele encontrados até aqui, entendendo que neste quadro estão presentes problemas e soluções que podem ser de imprescindível contribuição para a renovação e desenvolvimento da Psicologia do Trabalho e Organizacional no Brasil e no mundo.

A noção de competência e seu significado de restituição do trabalho ao trabalhador, de retomada da prerrogativa de tomar iniciativas, portanto, de reexercitar o poder de agir, de interferir nos destinos, de regular o trabalho, de poder modulá-lo segundo o perfil de cada trabalhador, de transformar o status quo das organizações, inclusive no que tange ao posicionamento da hierarquia e aos formatos organizacionais, é, sem sombra de dúvidas, o retorno à vida da subjetividade, sufocada por longo tempo na lógica taylorista, que ignora a contribuição que os humanos (exceto aqueles contratados para pensar o trabalho) podem oferecer, individual e coletivamente, à organização do trabalho. A crise dos anos 1970 coloca em evidência a incapacidade do taylorismo de responder as novas demandas econômicas, políticas, sociais, tecnológicas, organizacionais. Um novo modelo precisava ser gestado para fazer face aos novos desafios. O modelo da competência se apresenta nesse momento com um grande potencial, melhor dizendo, com um potencial revolucionário, semente de desdobramentos que poderiam se revelar surpreendentes. A retomada da respiração subjetiva, a possibilidade de reconectar a inteligência e o trabalho, de reafirmação do trabalhador como sujeito, desbravador, autor, criador, inovador, alguém que abre caminhos, que enfrenta os problemas e constrói soluções e não meramente um "executor", um expectador dos acontecimentos, um anônimo que segue caminhos traçados por outros, que cumpre instruções, diretrizes nascidas nos gabinetes dos experts, é certamente um quadro mais favorável à saúde mental, questão de interesse primeiro da Psicologia. Nas explorações do modelo da competência, encontramos o homem em busca de um ambiente onde a subjetividade 
encontre vias de expressão, onde o corpo se julgue confortável, onde a produtividade possa coexistir com a busca da qualidade e que esses objetivos se articulem com um trabalho seguro e saudável.

Os desdobramentos que esse encaminhamento revolucionário pode ter são, ainda, conforme assinala o próprio Zarifian, uma incógnita, algo que encontra resistências profundas, especialmente ao nível de quem tem a chave de muitas mudanças. As tensões são inúmeras, não há como ignorar, embora as pressões por mudança sejam bastante fortes. O que vai vingar, o que vai nascer desse embate constitui um mistério. A Psicologia do trabalho e das organizações tem aí um papel importante, de insistir teimosamente na afirmação das condições em que os humanos possam produzir obras que contribuam para crescer esse gigantesco patrimônio cultural da humanidade. O modelo da competência pode ensejar transformações profundas na direção de uma participação implicada dos homens não apenas nos assuntos do trabalho, da produção, mas da cidade, da pólis. Para tanto, determinadas condições precisam ser buscadas. Do contrário, estaremos diante de uma tecnologia gerencial sofisticada que, no entanto, encerra em outras grades o potencial criativo dos humanos.

Obviamente que os limites desse texto permitiram apenas apontar algumas questões, ficando seu desenrolar para textos futuros. Reconhece-se que nenhum texto será capaz de esgotar a temática em questão, principalmente quando esta é cenário de debates cada vez crescentes - como é o caso das competências - mas se espera que ele tenha contribuído para reflexões importantes sobre este tema. 
Amaro, R. A. (2008). Da qualificação à competência: deslocamento conceitual e individualização do trabalhador. RAM. Revista de Administração Mackenzie, 9(7):89-111.

Borges, M. E. S. (2006). O rei está nu: tramas e urdiduras por uma gestão do trabalho (Tese de Doutorado), Universidade do Estado do Rio de Janeiro, Rio de Janeiro, RJ.

Dejours, C. (2013). A sublimação, entre sofrimento e prazer no trabalho. Revista Portuguesa de Psicanálise, 33(2):9-28.

Fleury, M. T. L., \& Fleury, A. (2001). Construindo o conceito de competência. Revista de Administração Contemporânea, 5(n esp.): 183-196.

Heloani, R. (2003). Gestão e Organização no capitalismo globalizado: história da manipulação psicológica no mundo do trabalho. São Paulo, SP: Atlas.

Ramos, M. N. (2001). A pedagogia das competências: autonomia ou adaptação? São Paulo, SP: Cortez.

Schwartz, Y., \& Durrive, L. (Orgs.). (2010). Trabalho \& ergologia: conversas sobre a atividade humana (2a ed. rev. ampl.). Niterói, RJ: Editora da UFF.

Stroobants, M. (2006). Competência. Laboreal, 2(2): 78-79.

Zarifian, P. (1996a). A gestão da e pela competência. In: Seminário Educação Profissional, Trabalho e Competências. Rio de Janeiro, RJ: Centro Internacional para a Educação, Trabalho e Transferência de Tecnologia. [Mimeo].

(2002). Engajamento subjetivo, disciplina e controle. Novos Estudos Cebrap, (64): 27.

(2001b). Mutação dos sistemas produtivos e competências profissionais: a produção industrial de serviço (pp. 67-94). In M. S. Salerno, Relação de serviço: produção e avaliação. São Paulo, SP: SENAC. (1995b). Novas formas de organização e modelo da competência na indústria francesa (pp. 1-17). In: Anais do $1^{\circ}$ Workshop Implementação de Novas Formas de Organização do Trabalho, 1995, São Paulo, SP.

(2003). O modelo da competência: trajetória histórica, desafios atuais e propostas. São Paulo, SP: Senac São Paulo.

(1996b). O modelo das competências e suas consequências para os ofícios profissionais. In: Seminário Internacional Educação Profissional, Trabalho e Competências. Rio de Janeiro, RJ: Centro Internacional para a Educação, Trabalho e Transferência de Tecnologia.

(2001a). Objetivo competência: por uma nova lógica. São Paulo, SP: Atlas.

(1995a). Organização qualificante e modelos de competência: que razões? Que aprendizagens? Revista Europeia de Formação Profissional, 3(5): 5-10.

(1997). Por uma sociologia da confrontação (a propósito da interdisciplinaridade). Revista Latinoamericana de Estudos do Trabalho, 3(5): 74-82.

. (1991). Trabalho e comunicação nas indústrias autoatizadas. Tempo Social, 3(12): 119-130.

(2001c). Valor, organização e competência na produção de serviço: esboço de um modelo de produção de serviço (pp. 97-149). In M. S. Salerno, Relação de serviço: produção e avaliação. São Paulo, SP: SENAC.

Zarifian, P. (1999). El modelo de la competencia y sus consecuencias sobre el trabajo y los ofícios profesionales. Cinterfor, pp. 33-46. Recuperado em 10 de março de 2011. Obtido em http://www.cinterfor.org.uy/ public/spanish/region/ampro/cinterfor/ publ/ papel/8/pdf/papel8_3.pdf 


\section{Claudia Maria Pereira de Lima}

Mestre em Psicologia pela Universidade Federal da Paraíba - UFPB. Brasil.

Psicóloga Organizacional da Empresa Brasileira de Serviços.

E-mail: claudinhampl@hotmail.com

\section{Paulo César Zambroni-de-Souza}

Doutor em Psicologia Social pela Universidade do Estado do Rio de Janeiro - UERJ. Brasil. Docente do Departamento de Psicologia da Universidade Federal da Paraíba - UFPB. Brasil. E-mail: paulozamsouza@yahoo.com.br

\section{Anísio José da Silva Araújo}

Doutor em Ciências pela Fundação Oswaldo Cruz. Brasil.

Docente adjunto da Universidade Federal da Paraíba - UFPB. Brasil.

E-mail: anisiojsa@uol.com.br

\section{Endereço para envio de correspondência:}

Rua Saffa Said Abel da Cunha, 105. Tambauzinho. CEP: 58042-220. João Pessoa - PB. Brasil.

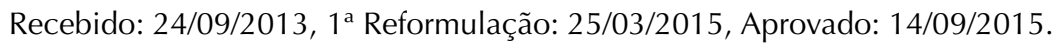

